\title{
3C-6H transformation in heated cubic silicon carbide 3C-SiC
}

\author{
S.I. Vlaskina ${ }^{1,2}$, G.N. Mishinova ${ }^{3}$, V.I. Vlaskin ${ }^{4}$, V.E. Rodionov ${ }^{2}$, G.S. Svechnikov ${ }^{2}{ }^{3}$ \\ ${ }^{1}$ Yeoju Institute of Technology (Yeoju University), 338 Sejong-ro, Yeoju-eup, Yeoju-gun, \\ Gyeonggi-do, 469-705 Korea \\ ${ }^{2}$ V. Lashkaryov Institute of Semiconductor Physics, National Academy of Science of Ukraine, \\ 45, prospect Nauky,03028 Kyiv, Ukraine; E-mail: businkaa@mail.ru \\ ${ }^{3}$ Taras Shevchenko Kyiv National University, 64, Volodymyrs'ka str., 01033 Kyiv, Ukraine \\ ${ }^{4}$ Interlink Electronics, Inc. 546, Flynn Road, Camarillo, CA 93012, USA
}

\begin{abstract}
Results of the research on the photoluminescence study of the $3 \mathrm{C}-6 \mathrm{H}-\mathrm{SiC}$ phase transformation are presented. $3 \mathrm{C}-\mathrm{SiC}$ crystals with in grown $3 \mathrm{C}-6 \mathrm{H}$ transformation and pure perfect $3 \mathrm{C}-\mathrm{SiC}$ crystals grown by the Tairov-Tsvetkov method without a polytypes joint after high temperature annealing were investigated. Fine structure at the energy of $E=2.73,2.79 \mathrm{eV}, E=2.588 \mathrm{eV}$, and $E=2.48 \mathrm{eV}$ that appeared after annealing was described. The role of stacking faults in the process of structure transformation was investigated.
\end{abstract}

Keywords: polytype, silicon carbide, photoluminescence spectrum, 3C-6H transformation.

Manuscript received 02.02.11; revised manuscript received 21.06.11; accepted for publication 14.09.11; published online 30.11.11.

\section{Introduction}

Silicon carbide crystallizes in different structures. This behavior was discovered about 100 years ago (in 1912) and called polytypism. More than $200 \mathrm{SiC}$ polytypes were investigated [1], the numerous growth technologies were used [2,3], a lot of high-power, high frequency, high-temperature and radiation-resistant devices with excellent performance were made. However, the control of polytype in substrates and in the devices is an open question and a great challenge.

The $\mathrm{SiC}$ polytypes can be described by different stacking of Si-C layers perpendicular to the direction of the closed-packed plane $\{111\}$ in cubic or $\{0001\}$ in hexagonal $\mathrm{SiC}$. The stacking sequences of the two closepacked lattices are fcc: ABCABC hcp: ABABAB. The agglomeration of vacancies on the $\{111\}$ planes removes parts of $\{111\}$ plane and produces a stacking fault because the stacking sequence of $\mathrm{ABCABCA}$ has changed to the faulty sequence of $\mathrm{ABCABABC}$.

Burgers vectors of these dislocations are $\mathbf{b}= \pm a / 6\{112\}$ and these types of two-dimensional defects are called Shockley partial dislocations. The disc of vacancies is bordered by an edge dislocation. Shockley partials are "slipping" dislocations. The disk of agglomerated interstitials creates the stacking sequences of ABCABACABCA. Burgers vectors of these dislocations are $\mathbf{b}= \pm a / 3(111)$ and these types of two- dimensional defects are called Frank partial dislocation. Frank partials are "sitting" dislocations [4].

The dislocation activity taking place during plastic deformation is mediated by partial dislocations being nucleated and absorbed at grain boundaries [5].

The generation of stacking faults defects in the device active region causes degradation of $\mathrm{SiC}$ devices during long-time operation or during heating of the substrate or devices [6-13]. Therefore, power device degradation takes place due to phase transformations in $\mathrm{SiC}$ devices. The study of the phase transformation $3 \mathrm{C}$ $6 \mathrm{H}-\mathrm{SiC}$ showed that multilayer polytypes were formed during this transformation.

So, it is clear that the investigation of the phase transformation is very important for the development of $\mathrm{SiC}$ technology, which is used in the automotive, space and environmental industry. This paper presents the results of the research on photoluminescence study of $3 \mathrm{C}-6 \mathrm{H}-\mathrm{SiC}$ phase transformation.

\section{Experiment}

The solid-state phase transformations can be studied in highly doped $\mathrm{SiC}$ crystals $[6,14,15]$ and in the pure single crystals. The strong donor-acceptor pair (DAP) photoluminescence takes place in the highly doped $\mathrm{SiC}$ crystals $[6,14]$ and the fine structure of PL associated with phase transformation can not be seen. 
In this paper very pure high-quality vapor grown $3 \mathrm{C}-\mathrm{SiC}$ crystals (grown by the sublimation method) was investigated. Platy $3 \mathrm{C}-\mathrm{SiC}$ crystals contain growth pyramids. Different sides of this pyramid have different resistance due to different impurity concentration and defect content [16]. Very high-quality special one pyramid side $3 \mathrm{C}-\mathrm{SiC}$ crystals containing heterostructures of SiC-polytypes, namely, the cubic polytypic 3C-SiC and hexagonal polytypic $6 \mathrm{H}-\mathrm{SiC}$ in grown $(3 \mathrm{C}-6 \mathrm{H}-\mathrm{SiC}$ grown hetero-structures) were investigated as original structures, and after high temperature heating.

\section{1. $3 \mathrm{C}$-SiC crystals with as grown $3 \mathrm{C}-6 \mathrm{H}$ transformation}

Pure high-quality light-yellow 3C-SiC single crystals grown by the sublimation method [17] with natural heterostructure 3C-6H-SiC (cubic to hexagonal) were investigated. Non-compensated impurity nitrogen concentration was about $\left(N_{D}-N_{A}\right)=10^{17} \mathrm{~cm}^{-3}, N_{D}$ was about $5 \times 10^{17} \mathrm{~cm}^{-3}$. Three different areas were identified by colors in crystals: light-yellow area for $3 \mathrm{C}-\mathrm{SiC}$, lightgrey area for intermediate joint $3 \mathrm{C}-6 \mathrm{H}$ polytypes and noncolored or light-green area for $6 \mathrm{H}-\mathrm{SiC}$.

Photoluminescence was not found in the crystals at room temperature $(300 \mathrm{~K})$ or at liquid nitrogen temperature $(77 \mathrm{~K})$. Three different photoluminescence spectra were observed at liquid helium temperature $(4.2 \mathrm{~K})$ : for the $3 \mathrm{C}-\mathrm{SiC}$ area, for the intermediate joint $3 \mathrm{C}-6 \mathrm{H}-\mathrm{SiC}$ area and for the $6 \mathrm{H}-\mathrm{SiC}$ area. The low temperature photoluminescence (LTPL) spectra of the crystal with the natural polytypes joint $3 \mathrm{C}-6 \mathrm{H} \mathrm{SiC}$ at the different photoluminescence excitation are shown in Fig. 1. Energy of $2.681 \mathrm{eV}$ is not enough for excitement of $3 \mathrm{C}$-SiC exciton luminescence.

Laser energy of $3.283 \mathrm{eV}$ excites linear nitrogen exciton spectra in cubic SiC. The series of peaks at (4800-5700) $\AA$ gives evidence that the shot-wavelength part of the spectrum is at the energy level which is more than the exciton band gap $E_{g x} 3 \mathrm{C}-\mathrm{SiC}(2.349 \mathrm{eV})$. This can be explained by formation of the structures with bigger $E_{g}$ than cubic $\mathrm{SiC}$, namely hexagonal $\mathrm{SiC}$.

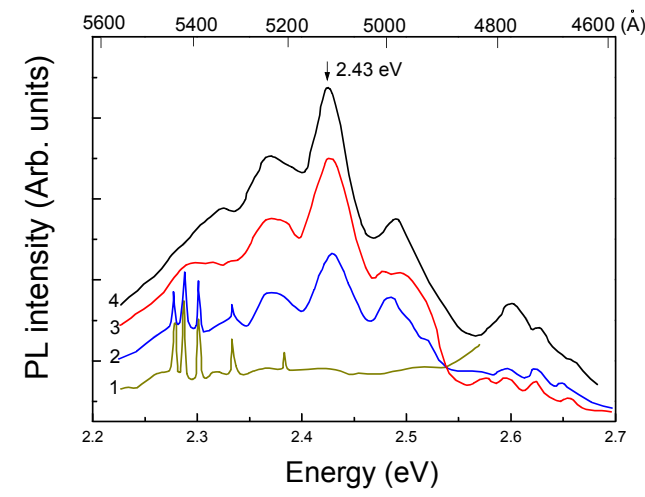

Fig. 1. Low temperature photoluminescence (LTPL) spectra $(4.6 \mathrm{~K})$ of $3 \mathrm{C}-6 \mathrm{H}-\mathrm{SiC}$ polytypes joint at photoluminescence excitement: $1-2.681,2-2.915,3-3.109,4-3.283 \mathrm{eV}$.
At the phase transformation $6 \mathrm{H}-3 \mathrm{C}$ SiC [14] maximums at the (4800-5700) $\AA$ have been reported as the "disorder area" due to the formation of multilayer polytypes.

The area of $4500-4800 \AA$ is usual associated with DAP luminescence in hexagonal SiC. Linear highresolution spectra are related to the nitrogen bound excitons in 3C-SiC [18] (area of photo-luminescence excitement covers $3 \mathrm{C}-\mathrm{SiC}$ part of crystal).

The grey intermittent area between light yellow cubic $\mathrm{SiC} 3 \mathrm{C}-\mathrm{SiC}$ and uncolored hexagonal $6 \mathrm{H}-\mathrm{SiC}$ emits at 4800-5600 $\AA$. The yellow part of the crystal has linear structure of nitrogen bound exciton complexes with non-phonons line $\mathrm{O}\left(E_{g x}=2.379 \mathrm{eV}\right)$. Divacancies centers spectra with non-phonon line at A $(E=1.975 \mathrm{eV})$ is absent.

The spectra of the yellow part of the SiC-crystal with natural polytypes joint are recorded at $4.2 \mathrm{~K}$ at the maximum intensiveness of exciton luminescence and at the maximum intensiveness of the light radiation $5100 \AA$. The linear structure of the nitrogen bound exciton certifies the highest quality of the pure cubic part of this crystal with in grown joint polytypes defects.

The LTPL spectra at different temperatures $(4.5,7$, 10 and $15 \mathrm{~K}$ ) from the polytypes $3 \mathrm{C}-6 \mathrm{H}$ joint area at the same energy of exciting light shown that the extinction of luminescence occurs with rising temperature. The photoluminescence disappears at $77 \mathrm{~K}$. In the LTPL spectra at 4.3 and $30 \mathrm{~K}$ of the uncolored $6 \mathrm{H}-\mathrm{SiC}$ part of the crystal with joint polytypes the luminescence at (4500-4800 $\AA$ ) are interpreted as the usual donoracceptor spectra (DAP) of $6 \mathrm{H}-\mathrm{SiC}$. The extinction of luminescence from the hexagonal part and the flaming up of luminescence of the cubic part takes place.

\subsection{C-SiC crystals with in grown 3C-6H transformation after high temperature annealing}

Crystals with natural polytypes joints were annealed for one hour at the temperature of $2000{ }^{\circ} \mathrm{C}$ in argon atmosphere. The structure changed after annealing (Photo 1a) and reflexes from hexagonal polytypes can be clearly seen on Laye-patterns (Photo 1a). It means that phase transformation of 3C-6H-SiC occurs. The LTPL spectra changed also. Maximum at $E=1.97 \mathrm{eV}$ (nonphonon line) appeared. Vacancies center (silicon vacancies) can be responsible for this radiation (W.J. Choyke) $[1,2]$. It means that vacancies generation in $3 \mathrm{C}-\mathrm{SiC}$ was observed after annealing of $3 \mathrm{C}-\mathrm{SiC}$ crystals and phase transformation similar to the $3 \mathrm{C}-6 \mathrm{H}-$ $\mathrm{SiC}$ transformation occurs $[6,14]$.

Short wavelength luminescence $\left(E>E_{g 3 \mathrm{C}-\mathrm{SiC}}\right)$ in the area of (2.5-2.8) eV was activated. Maximal changes were observed in the area of the natural phase transformation namely in the area of the natural polytypes joint. These changes in LTPL spectra after annealing are shown in Fig. 2. The LTPL spectra were registered from the different parts of the crystals with grown polytypes joint. Curve 1 corresponds to the $6 \mathrm{H}-$ 
$\mathrm{SiC}$ area, curve 2 corresponds to the structure with onedimension disorder on the boundary between hexagonal and cubic polytypes, curve 3 corresponds to the $3 \mathrm{C}-\mathrm{SiC}$ part of crystal.

The LTPL $(T=4.3 \mathrm{~K})$ spectra of $3 \mathrm{C}-\mathrm{SiC}$ crystal with natural polytypes joint after annealing for one hour at $T=2000{ }^{\circ} \mathrm{C}$ (from $\alpha$-phase - curve 1 and from transition area $\beta \rightarrow \alpha-$ curve 2) are shown in Fig. 3 . Phonon replicas (TA, TO, LA and LO) of exciton $(\mathrm{O})$ are indicated.

\subsection{Pure 3C-SiC crystals after high temperature annealing}

Pure perfect 3C-SiC crystals (grown by Tairov-Tsvetkov method) without the polytypes joint were annealed, too, and structural and spectroscopic changes were also observed. Reflexes from hexagonal polytypes appeared on Laye-patterns (Photo 1b). It means that phase transformation in pure perfect $3 \mathrm{C}-\mathrm{SiC}$ occurs too after annealing.

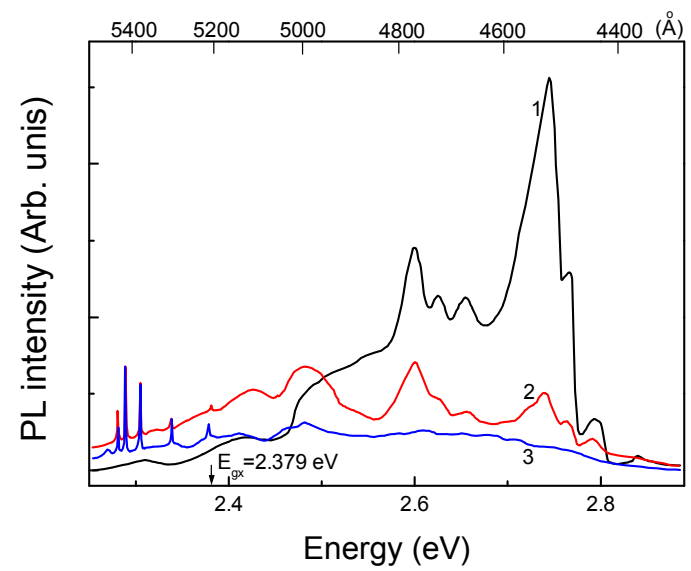

Fig. 2. LTPL spectra registered from the different parts of 3C$\mathrm{SiC}$ crystal with grown polytypes joint after annealing for 1 hour at $2000^{\circ} \mathrm{C} .1-6 \mathrm{H}-\mathrm{SiC}$ area, 2 - the structure with onedimension disorder on the boundary between hexagonal and cubic polytypes, $3-3 \mathrm{C}-\mathrm{SiC}$ part of the crystal at the interface.

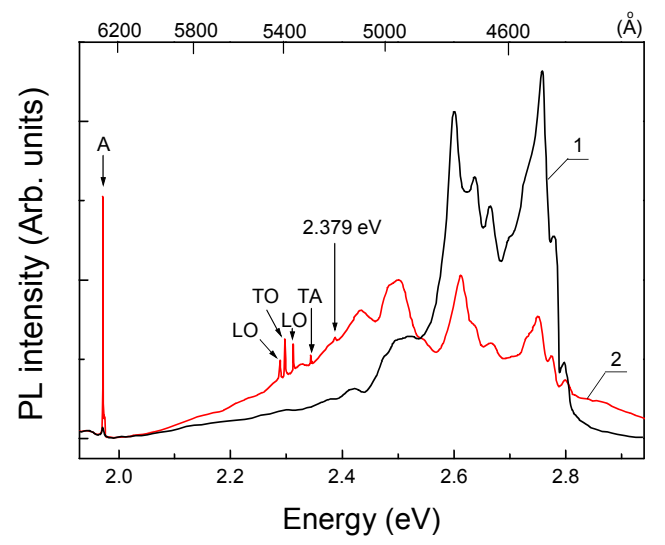

Fig. 3. LTPL spectra $(T=4.3 \mathrm{~K})$ of $3 \mathrm{C}-\mathrm{SiC}$ crystal with natural polytypes joint after annealing for one hour at $T=2000^{\circ} \mathrm{C} .1$ from $\alpha$-phase, 2 - from transition $\beta \rightarrow \alpha$ area.

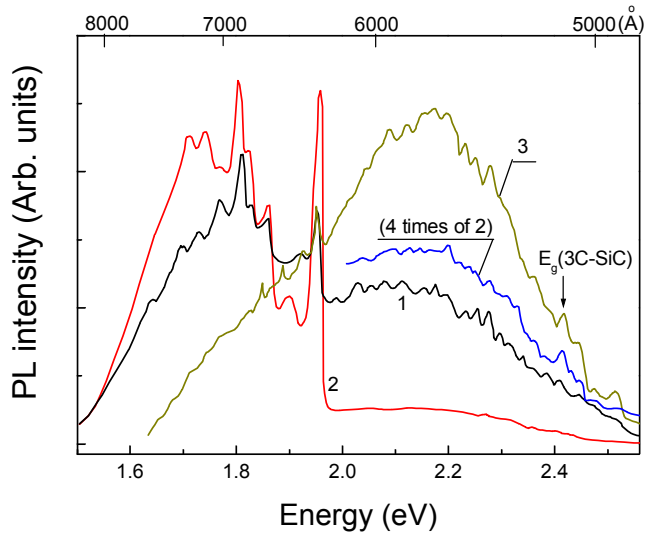

Fig. 4. LTPL spectra of pure perfect crystals after annealing. 1 - after annealing during 1 hour, $T=2000{ }^{\circ} \mathrm{C} ; 2-$ after annealing during 6 hour, $T=2000^{\circ} \mathrm{C} ; 3-$ after annealing during 10 hour, at $T=2000{ }^{\circ} \mathrm{C}$.

Pure perfect $3 \mathrm{C}$-SiC crystals demonstrated LTPL at $4.2 \mathrm{~K}$ usual for $3 \mathrm{C}-\mathrm{SiC}$, nitrogen-exciton complexes. The pure $3 \mathrm{C}-\mathrm{SiC}$ crystal did not have PL at $77 \mathrm{~K}$. After annealing for 1,6 and 10 hours at $T=2000^{\circ} \mathrm{C}$ LTPL at $77 \mathrm{~K}$ appeared (the same as in case of the crystals with joint 3C-6H SiC transformation). The LTPL spectra of pure perfect crystals after annealing are shown in Fig. 4 at $77 \mathrm{~K}$. It is clear that the lines at $E=1.97 \mathrm{eV}$ and $1.8 \mathrm{eV}$ (divancancies lines) appear at the beginning of annealing (when crystals are annealed for 1 hour). Later, the spectra is shift to a short-wave length area and emission appears at $E>E_{g} 3 \mathrm{C}-\mathrm{SiC}$, namely at $(2.4-3.0) \mathrm{eV}$.

So, if short-wave length luminescence was activated in crystal with the natural $3 \mathrm{C}-6 \mathrm{H}-\mathrm{SiC}$ joint after annealing at the area of transformation for 1 hour, the same result takes place in perfect crystals after annealing for 6-10 hours.

And line-spectra due to the divacancies centers with non-phonon line A $(E=1.975 \mathrm{eV})$ appear only after long time annealing for 6-10 hours (in crystal with the natural $3 \mathrm{C}-6 \mathrm{H}-\mathrm{SiC}$ joint after annealing at the area of transformation for 1 hour).

The LTPL spectra from polytypes joint area of crystal with the in grown $3 \mathrm{C}-6 \mathrm{H}-\mathrm{SiC}$ polytypes joint combined with luminescence spectra of excitation before and after annealing for 1 hour, $T=2000{ }^{\circ} \mathrm{C}$ are shown in Fig. 5. It is clear that fine structure appears at the energies $E=2.73 ; \quad 2.79 \mathrm{eV}, \quad E=2.588 \mathrm{eV}, \quad$ and $E=2.48 \mathrm{eV}$. Fine structure was not detected in the crystal before annealing.

\section{Results and discussions}

The cubic polytype $\beta$-SiC becomes unstable at the temperature of $T>1500{ }^{\circ} \mathrm{C}$ and $\beta \rightarrow \alpha$ transformation begins. Close-packed layers (111) shift and an increase in numbers and area of spreading of stacking faults are observed like $\alpha \rightarrow \beta$ transformation [19]. The stacking faults spread in volume uniformly after annealing. 


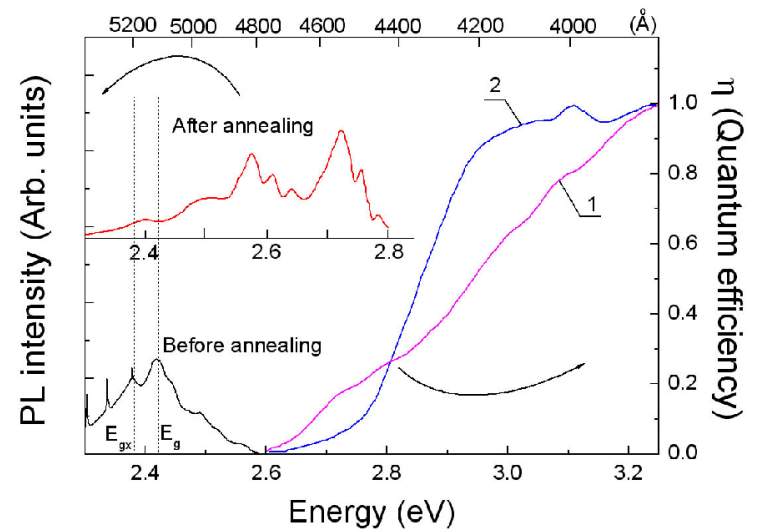

Fig. 5. LTPL spectra from polytypes joint area (of the crystal with as grown $3 \mathrm{C}-6 \mathrm{H}-\mathrm{SiC}$ polytypes joint) combined with spectra of luminescence excitation $(\eta): 1-$ before annealing, 2 - after annealing during 1 hour $\left(T=2100^{\circ} \mathrm{C}\right)$.
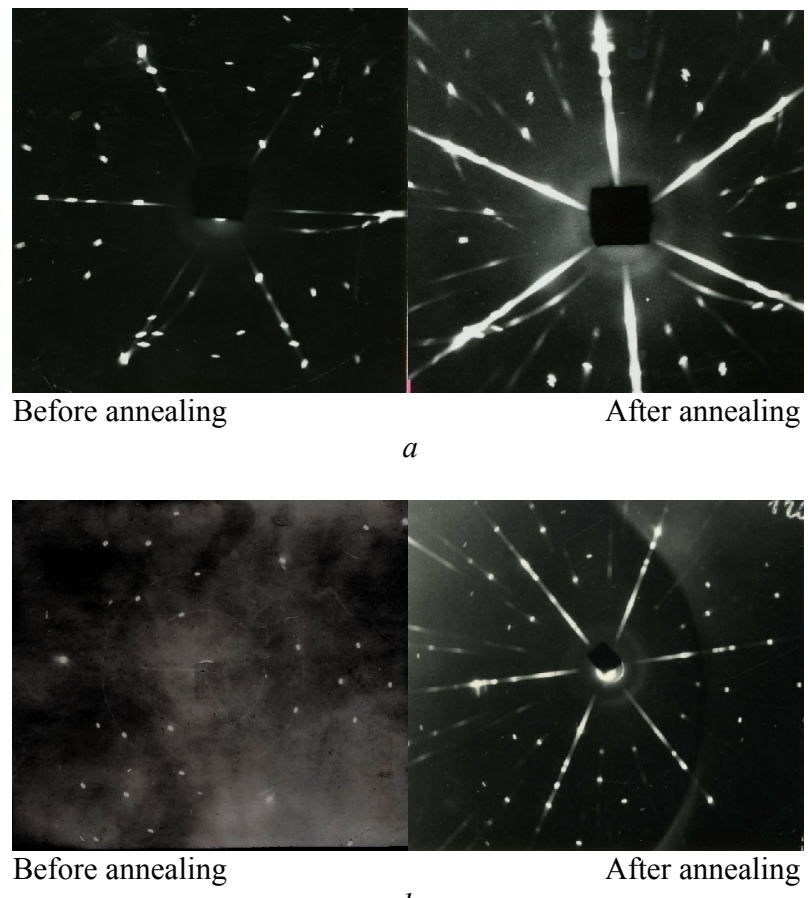

$b$

Photo 1. a) X-ray diffraction pattern of $3 \mathrm{C}-\mathrm{SiC}$ with joint polytypes 3C-6H-SiC (as grown before annealing and after annealing during 1 hour at the temperature $2100{ }^{\circ} \mathrm{C}$ ); b) X-ray diffraction pattern of pure perfect $3 \mathrm{C}-\mathrm{SiC}$ (as grown before annealing and after annealing for 10 hours at temperature $\left.2000{ }^{\circ} \mathrm{C}\right)$.

$\beta \rightarrow \alpha$ transformation starts from natural polytypic joint $3 \mathrm{C}-6 \mathrm{H}-\mathrm{SiC}$ exactly as from seeds. This process spreads onto some sectors with changing of crystal's color (Fig. 1).

Vacancies are generated in $\beta$-SiC during high temperature annealing. Short-wavelength luminescence at the area of $E>E_{g x 3 \mathrm{C}}$ is activated in the transmission zone on the boundaries of $\beta \rightarrow \alpha$ phases transformation. The disorder spectra very similar to the luminescence spectra described in [6] are pitched on a more-or-less intensive line of DAP radiation.

The pure perfect 3C-SiC grown by the TairovTsvetkov method crystals without the polytypes joint should be annealed for a longer time ( $t=6-10$ hours) for the same $\beta \rightarrow \alpha$ transformation and for the same spectra appearance.

It is clear that decoding of these spectra should give the answer to the question about $\beta \rightarrow \alpha$ transformation on the atomic scale.

\section{Conclusion}

$3 \mathrm{C}$-SiC crystals with in grown $3 \mathrm{C}-6 \mathrm{H}$ transformation and pure perfect $3 \mathrm{C}-\mathrm{SiC}$ crystals grown by the TairovTsvetkov method without the polytypes joint after high temperature annealing were investigated.

At the first stage vacancies were generated (line A at $E=1.973 \mathrm{eV}$ appeared). Some indicated linear spectra $(2.38-2.47 \mathrm{eV})$ on the DAP background were observed. These spectra were very intensive in the zone of $\beta \rightarrow \alpha$ transformation and gave evidence about disordering processes in cubic SiC. Pure perfect $3 \mathrm{C}-\mathrm{SiC}$ crystals should be annealed for a longer time ( $t=6-10$ hours) for the same $\beta \rightarrow \alpha$ transformation and for the same spectra appearance. Stacking faults play the main role in the process of structure transformation.

\section{References}

1. Silicon Carbide-recent Major Advances, Wolfgang J. Choyke, Hiroyuki Matsunami, Gerhard Pensl, 79, December, 2003.

2. Silicon Carbide: A Review of Fundamental Questions and Applications to Current Device Technology, Wolfgang J. Choyke, Hiroyuki Matsunami, Gerhard Pensl, June, 1997.

3. A. Fissel, About heteropolytypic structures: molecular beam epitaxy, characterization and properties of silicon carbide, in: Recent Research Developments in Material Science \& Engineering, ed. S.G. Pandalai (Transworld Research Network, Fort P.O., Trivandrum, India). Vol. 1, Part 1, p. 277-327 (2002).

4. J. Fridel, Dislocations. Pergamon Press, 1964.

5. Tugas Mesin, Nanocrystalline Metals: Stalking Faults and Slip. SABTU, October 11, 2008.

6. S.W. Lee, S.I. Vlaskina, V.I. Vlaskin, I.V. Zaharchenko, V.A. Gubanov, G.N. Mishinova, G.S. Svechnikov, V.E. Rodionov, S.A. Podlasov, Silicon carbide defects and luminescence centers in current heated 6H-SiC // Semiconductor Physics, Quantum Electronics and Optoelectronics, 13(2), p. 24-29 (2010).

7. S. Soloviev and D. Cherednichenko, Y. Gao, A. Grekov et al., Forward voltage drop degradation in diffused SiC p-i-n diodes // J. Appl. Phys. 95(8), (2004). 
8. M.E. Twing, R.E. Stahlbush, M. Fatemi, S.D. Arthur, J.B. Fedison, J.B. Tucker, and $\mathrm{S}$. Wang, Extended defects in $4 \mathrm{H}-\mathrm{SiC}$ p-i-n diodes // MRS webside.

9. S.G. Sridhara, F.H.C. Carlsson, J.P. Bergman, and E. Janzén, Luminescence from stacking faults in 4H SiC // Appl. Phys. Lett. 79, p. 3944 (2001).

10. Robert E. Stahlbush, Sei-Hyung Ryu, Qingchun Zhang, Husna Fatima, Sarah Haney and Anant Agarwal, Power device degradation due to dislocations and stacking faults in $4 \mathrm{H}-\mathrm{SiC}$ epitaxy // MRS-spring meeting 2008, Symposium D: Silicon Carbide - Materials, Processing, and Devices, San-Francisco, CA, March 24-28, 2008.

11. Joshua D. Caldwell, Robert E. Stahlbush, Orest J. Glembocki, Karl D. Hobart, Eugene Imhoff, Marko J. Tadjer and Kendrick X. Liu, Influence of Shockley stacking fault propagation and contraction on the electrical behavior of $4 \mathrm{H}-\mathrm{SiC}$ bipolar and unipolar devices // MRS-spring meeting 2008, Symposium D: Silicon Carbide - Materials, Processing, and Devices, San-Francisco, CA, March 24-28, 2008.
12. W.R.L. Lambrecht and M.S. Miao // Phys. Rev. B 73, $155312(2006)$.

13. A. Agarwal, H. Fatima, S. Haney, et al. // IEEE Electron Device Lett. 28, p. 587 (2007).

14. S.I. Vlaskina, D.H. Shin, $6 \mathrm{H}$ to $3 \mathrm{C}$ polytype transformation in silicon carbide // Jpn. J. Appl. Phys. 38, p. 27-29 (1999).

15. S.I. Vlaskina, Mechanism of $6 \mathrm{H}-3 \mathrm{C}$ transformation in $\mathrm{SiC} / /$ Semiconductor Physics, Quantum Electronics and Optoelectronics, 5(2), p. 252-155 (2002).

16. L.S. Aivazova, Yu.M. Altaiskii, V.G. Sidyakin, The bulk-gradient photo-emf and the homogeneity of $\beta$-SiC single crystals // Izvestia Vysshikh Uchebnikh Zavedenii, Fizika, No. 10, p. 113-114, October, 1972 (in Russian).

17. Yu.M. Tairov, Growth of bulk SiC // Materials Sci. and Eng. B, 29(1-3), p. 83-84 (January, 1995).

18. T.G. Pensl and W.J. Choyke // Physica B, 185, p. 264 (1993).

19. I.S. Gorban, G. Mishinova, The bases of luminescence diagnostic of dislocation structure of SiC crystals // Proc. SPIE, 3359, p. 187-196 (1997). 